\title{
Nuclear Swelling Measurement
}

National Cancer Institute

\section{Source}

National Cancer Institute. Nuclear Swelling Measurement. NCI Thesaurus. Code

C114213.

The determination of the expansion of the nucleus of the cells in a sample. 